\title{
Substance Administration ICSR Terminology
}

National Cancer Institute

\section{Source}

National Cancer Institute. Substance Administration ICSR Terminology. NCI Thesaurus.

Code C99175.

Terminology used in Individual Case Safety Reports to specify a type of substance administration. 